\title{
MECHANISM OF STERIGMATOCYSTIN BIOSYNTHESIS REGULATION BY PH IN ASPERGILLUS NIDULANS
}

\author{
Francisco Delgado-Virgen, Doralinda Guzman-de-Peña*
}

Departamento de Biotecnología y Bioquímica. Centro de Investigación y de Estudios Avanzados del IPN Campus Guanajuato. Km. 9.6 Libramiento Norte Irapuato-León. Irapuato, Guanajuato. 36821, México.

Submitted: February 23, 2009; Returned to authors for corrections: April 26, 2009; Approved: May 15, 2009.

\begin{abstract}
External $\mathrm{pH}$ constitutes one of the most important environmental factors that control growth, metabolism and differentiation in microorganisms, including fungi. We have analyzed the effect of external $\mathrm{pH}$ on sterigmatocystin biosynthesis in Aspergillus nidulans. It was observed in repeated experiments that alkaline $\mathrm{pH}$, in opposition to acid $\mathrm{pH}$, increased sterigmatocystin production and the transcript levels of aflR, the master gene that regulates expression of the sterigmatocystin cluster in A. nidulans.

It is known that $\mathrm{pH}$ effects in fungi operate mostly through the $\mathrm{Pal} / \mathrm{Pac}$ signaling pathway, originally described in Aspergillus nidulans. Accordingly, we studied the role of this signaling pathway in ST biosynthesis. It was observed that aflR transcript levels were increased in the "alkalinity mimicking" mutant pacC $c^{c} 14$ and were minimal in the "acidity mimicking" mutant palA1. No sterigmatocystin was produced by palAl or pacC-mutants at neither acid or alkaline $\mathrm{pH}$ of incubation. Finally, fluG and flbA, genes known to regulate both conidiation and sterigmatocystin synthesis upstream in the regulatory cascade, were up-regulated at alkaline $\mathrm{pH}$.
\end{abstract}

Key words: Aspergillus nidulans; $\mathrm{pH}$; sterigmatocystin; pacC

\section{INTRODUCTION}

Mycotoxins are a group of toxic secondary metabolites produced by fungi, mainly from the genera Aspergillus, Penicillium and Fusarium (22). They are frequently found contaminating a wide variety of food and feed, representing a serious threat to human and animal health and causing severe economic losses (8). Aflatoxins (AF) are among the most studied mycotoxins. Aflatoxins are produced mainly by Aspergillus flavus and A. parasiticus. Aflatoxin $\mathrm{B}_{1}$ is not only toxic but also teratogenic and mutagenic; being the most potent carcinogenic compound found in nature (15).
Studies using the model organism A. nidulans, which produces the AF precursor sterigmatocystin (ST), have led to a better understanding of the biosynthetic steps involved in AF production (4). The fact that the mycotoxin gene clusters from A. nidulans and A. parasiticus have high homology (25) has also been helpful in the study of AF/ST synthesis and regulation.

Among the most important physiological determinants that regulate AF/ST production in Aspergilli are the carbon and nitrogen sources, and the $\mathrm{pH}$ of the medium. Simple carbohydrates, such as glucose and sucrose, favor AF biosynthesis in A. parasiticus and ST biosynthesis in $A$. 
nidulans (19). It is also known that while ammonium favors AF biosynthesis in A. parasiticus, it inhibits ST production in A. nidulans (13). However, studies on the effect of $\mathrm{pH}$ on mycotoxin synthesis have often produced complex and at times contradictory results; e.g. data in the literature have reported either a positive $(9,11,18)$ or no effect (5) of acid $\mathrm{pH}$ in aflatoxin biosynthesis by A. flavus and/or $A$. parasiticus, but no information exists on the mechanism involved (for a discussion see (7)). It has also been reported that ST biosynthesis was stimulated by acid $\mathrm{pH}$ in $A$. nidulans (18).

Regulation of fungal metabolism by $\mathrm{pH}$ is mostly effected through the Pal/Pac signaling pathway, described for the first time in A. nidulans (6). PacC is a transcription factor activated at alkaline $\mathrm{pH}$ by the products of six pal genes that sense external $\mathrm{pH}$ and transduces the activating signal. PacC activation may lead to repression of genes expressed preferentially under acidic growth conditions, and upregulation of genes transcribed preferentially under alkaline growth conditions, including pacC itself (23). Loss of function mutations in any of the pal genes or pacC, lead to an "acidity mimicking" phenotype; i.e., display a pattern of gene expression similar to that of the wild-type strains grown under acidic conditions, independently of ambient $\mathrm{pH}$. In contrast, pacC constitutive mutants show an "alkalinity mimicking” phenotype, displaying a gene expression pattern similar to that of the wild-type strains grown under alkaline conditions, irrespective of ambient $\mathrm{pH}$ (see $(20,21)$ for helpful reviews). A pacC null mutant from A. nidulans displays an "acidity mimicking" phenotype, and exhibits poor growth and almost null conidiation, leading to the hypothesis that PacC might also be involved in development (23). Interestingly, Guzman-de-Peña and Ruiz-Herrera (12) found a correlation between AF biosynthesis and sporulation in A. parasiticus; and between both sexual and asexual sporulation and ST production in A. nidulans (13), thus linking mycotoxin synthesis and differentiation in Aspergilli. Further on, several reports that proposed a model G-
protein/cAMP/PKA signaling pathway that connected growth, conidiation and ST production in A. nidulans have been published $(3,14)$.

Taking into consideration all these data, we proceeded to analyze the regulation of ST production by ambient $\mathrm{pH}$ in $A$. nidulans, and whether the Pal/Pac signaling pathway was or not involved in this process.

\section{MATERIALS AND METHODS}

\section{Strains and Growth Media and Conditions}

The strains used for these studies were Aspergillus nidulans FGSC26 (biAl, veAl), A. nidulans MAD002 (biAl, veA1), A. nidulans MAD134 (biA1, veal, palA1, wA3), A. nidulans MAD135 [biA1,veA1, pacC 14 (5-492)] and MAD812 (pantoB100, veAl, pacC ${ }^{+-2} 209$ ). A. nidulans FGSC26 and A. nidulans MAD002 are both good ST producers. A. nidulans MAD134 is a mutant strain unable to process the inactive form of $\mathrm{PacC}$, and therefore mimicks growth in acidic conditions regardless of the $\mathrm{pH}$ of the medium ("acidity mimicking" phenotype). On the other hand, the A. nidulans mutant strain MAD135 produces only a $\mathrm{pH}$-independent activated form of $\mathrm{PacC}$, mimicking growth in alkaline conditions, also regardless of the $\mathrm{pH}$ of the medium ("alkalinity mimicking" phenotype); and strain MAD812 has a stringent loss of function mutation. All MAD strains were kindly donated by Miguel A. Peñalva (Centro de Investigaciones Biológicas, Madrid, Spain).

All strains were kept at $4{ }^{\circ} \mathrm{C}$ as silica stocks. For conidia production, A. nidulans strains FGSC26, MAD002, MAD135, and MAD812 aliquots from the stocks were transferred to solid Kafer medium (16) with sodium nitrate as the sole nitrogen source and supplemented with $5 \%$ sucrose as carbon source, and grown for 5 days at $37^{\circ} \mathrm{C}$. A. nidulans MAD134 was grown at $28{ }^{\circ} \mathrm{C}$ on solid Kafer medium with ammonium tartrate and 5\% sucrose (acidic growth conditions) in order to avoid extragenic suppressors of the palA mutation (M. A. Peñalva, personal communication). 


\section{Spore suspensions}

Conidia were harvested by adding $10 \mathrm{ml}$ of a Triton X100 solution $(0.01 \%)$ to each Petri dish, counted with a hemocytometer and adjusted to the desired inoculum concentration with sterile distilled water. Before inoculation conidia suspensions were kept overnight at $4{ }^{\circ} \mathrm{C}$ to ensure an even germination.

\section{Growth conditions}

Conidia were inoculated into $100 \times 15 \mathrm{~mm}$ Petri dishes containing $50 \mathrm{ml}$ of liquid $\left(1 \times 10^{7}\right)$ or solid $\left(1 \times 10^{6}\right)$ Kafer medium (see Results) supplemented with 5\% sucrose and 70 $\mathrm{mM}$ sodium nitrate as carbon and nitrogen sources respectively, and incubated under static conditions at $37{ }^{\circ} \mathrm{C}$ for variable periods of time. In some experiments, $\mathrm{pH}$ of the media was adjusted with $100 \mathrm{mM}$ citrate buffer.

At the end of the incubation period, in liquid cultures the medium was separated from the mycelium by filtration. Mycelia were transferred to a Petri dish, washed with $10 \mathrm{ml}$ of distilled water containing $0.01 \%$ Triton X-100, and gently shaken to release the spores. This procedure was repeated twice. Mycelia were then dried at $75{ }^{\circ} \mathrm{C}$ for $24 \mathrm{~h}$, stored at room temperature in desiccators with silica gel as drying agent for another $24 \mathrm{~h}$, and weighed. The residual growth medium was processed immediately or stored at $4{ }^{\circ} \mathrm{C}$ until used. When mycelia were used for RNA extraction, they were collected by vacuum filtration, frozen with liquid nitrogen and stored at $-70{ }^{\circ} \mathrm{C}$ until used. When solid medium was used, after spore recovery ST was extracted as described below, agar was melted in a microwave oven, mycelia were recovered with the use of tweezers, washed with hot water, dried and weighed as above.

\section{ST quantitation}

ST was extracted from the mixture of culture medium, dry mycelium (see above) and conidia, with $50 \mathrm{ml}$ acetone for $30 \mathrm{~min}$, followed by $50 \mathrm{ml}$ chloroform by further $30 \mathrm{~min}$ (17). The organic phase was separated, filtered through anhydrous sodium sulfate and evaporated in a fume hood in a water boiling bath. The residue was resuspended in $500 \mu \mathrm{L}$ HPLC grade methanol and filtered through C-18 columns (Alltech).

Analysis and quantitation were performed by HPLC as previously described (13). The detection limit was $3 \mathrm{ng}$ ST in $20 \mu 1$ samples.

\section{RT-PCR analysis of the expression of genes encoding} proteins involved in growth and ST synthesis

Total RNA extraction was performed using TriZOL (Invitrogen). RNA purification was achieved using RNeasy mini Kit (Qiagen). RNA integrity was confirmed by electrophoresis in a $1.5 \%$ agarose gel in TAE $1 \mathrm{X}$. The expression levels of the genes $f l u G, f l b A, l a e A, p a c C$ and $a f l R$, were evaluated semi quantitatively by RT-PCR. Firststrand cDNA was obtained using $1 \mu \mathrm{g}$ of total RNA, adding 1 $\mu 1$ Oligo dT (Invitrogen), $1 \mu \mathrm{l}$ dNTP mix (10 $\mu \mathrm{M}$ each) and enough RNase-free water to adjust to $12 \mu$, heating the mix at $65{ }^{\circ} \mathrm{C}$ for $15 \mathrm{~min}$ and transferring it immediately to ice. 4 $\mu 1$ of $5 x$ RT Buffer, $2 \mu 1$ of DTT $0.1 \mathrm{M}$ and $1 \mu \mathrm{l}$ RNase OUT (Invitrogen) were added to each reaction, gently mixed and incubated at $42{ }^{\circ} \mathrm{C}$ for $2 \mathrm{~min}$. After that, $1 \mu \mathrm{l}$ Superscript II Reverse Transcriptase (Invitrogen) was added to each reaction for a final volume of $20 \mu \mathrm{l}$. RT conditions were: an initial incubation at $42{ }^{\circ} \mathrm{C}$ for $50 \mathrm{~min}$, followed by $15 \mathrm{~min}$ at $70{ }^{\circ} \mathrm{C}$. The cDNA derived from $0.1 \mu \mathrm{g}$ of total RNA was used as a template. PCR conditions were as follows: After an initial incubation at $94{ }^{\circ} \mathrm{C}$ for $3 \mathrm{~min}, 28$ cycles of $94{ }^{\circ} \mathrm{C}$ for $45 \mathrm{~s}, 54{ }^{\circ} \mathrm{C}$ for $1 \mathrm{~min}$ and $72^{\circ} \mathrm{C}$ for $1 \mathrm{~min}$ were performed, followed by a final incubation at $72{ }^{\circ} \mathrm{C}$ for $7 \mathrm{~min}$.

The PCR primers for each gene were as follows: 5'ACCCTAATGTTTATTTGGAT-3' (forward) and 5'TGGATAGGTCTGGTATAAGG-3' (reverse) for fluG; 5'-, TCCСТCAAATTCTCTCAATCGAACCGG-3' (forward) and 5'-GTAGAATGACAGGTTTTCTTCGCAGA-3' (reverse) for $f l b A$; 5'-GGTGACGATTTGTATAGTCC-3' (forward) and 5'-CTCTTCATGAAACTGGTTTC-3' (reverse) for laeA; 5'-GACTGACGGTATGACTTCTG-3' (forward) and 5'-GTTGGCAATGTAGTTACGTA-3' 
(reverse) for $p a c C$; 5'-GCCATCCTGTCTCCGAATAC-3' (forward) and 5'-CGAACCTCTACGACTGTCTTG-3' (reverse) for aflR; and 5' CCAAGGCCAACCGCGAGAAGATGAC-3 (forward) and 5'-AGGGTACATGGTGGTGCCGCCAGAC-3' (reverse) for $\gamma$-actin (control gene). Transcription levels were normalized by comparing the UV absorption intensity of the bands to that of $\gamma$-actin using ImageJ software (http://rsb.info.nih.gov/ij/).

\section{Statistical analyses}

Each experiment was repeated three to five times, and values presented in this paper are means of these replicates. Differences between means were evaluated by Tukey's Test $(\mathrm{p}=0.05)$ using SAS (version 6.12; SAS Institute, Cary, NC, USA). Coefficients of determination $\left(\mathrm{r}^{2}\right)$ and regression data are included in the corresponding results.

\section{RESULTS}

Relationship between initial $\mathrm{pH}$, growth and $\mathrm{ST}$ production

A. nidulans MAD002 (wild-type strain) was grown in Kafer medium at three different initial $\mathrm{pH}$ values for $72 \mathrm{~h}$. Growth, conidiation and ST synthesis were evaluated approximately every $12 \mathrm{~h}$. When initial $\mathrm{pH}$ was 4.61 , it was observed that only basal levels of ST were produced until 58 hours of incubation, ST synthesis being activated after this time (Table 1). Activation of ST synthesis occurred earlier when the initial $\mathrm{pH}$ value was raised $(58 \mathrm{~h}$ at initial $\mathrm{pH}=5.22$, and $46 \mathrm{~h}$ at $\mathrm{pH}=6.90$ ) (Table 1). As it may be seen in this table, time of activation of ST synthesis occurred when $\mathrm{pH}$ reached a value above 7.5. The amount of ST produced and mycelial growth at $72 \mathrm{~h}$ of incubation were also linearly increased as initial $\mathrm{pH}$ value of the medium increased $\left(\mathrm{r}^{2}=\right.$ 0.977 and $r^{2}=0.993$, respectively).

Table 1. Rate of growth and ST synthesis in A. nidulans MAD002 (wild-type).

\begin{tabular}{|c|c|c|c|c|}
\hline Initial pH & Incubation Time (h) & Final pH & Growth (mg DW) & Total Sterigmatocystin (ng) \\
\hline \multirow[t]{5}{*}{4.61} & 22 & 5.4 & $45.9 \mathrm{~A}$ & 0 \\
\hline & 34 & 6.2 & $62.8 \mathrm{~A}$ & $35 \mathrm{~A}$ \\
\hline & 46 & 6.8 & $104.8 \mathrm{~A}$ & $38 \mathrm{~A}$ \\
\hline & 58 & 7.2 & 211.2 & $43 \mathrm{~A}$ \\
\hline & 72 & 7.7 & 483.9 & 1,972 \\
\hline \multirow[t]{6}{*}{5.22} & 11 & 5.4 & $13.9 \mathrm{~A}$ & $65 \mathrm{~A}$ \\
\hline & 23 & 5.9 & $26.5 \mathrm{~A}$ & $83 \mathrm{~A}$ \\
\hline & 34 & 6.3 & $49.4 \mathrm{~A}$ & $38 \mathrm{~A}$ \\
\hline & 46 & 6.9 & $93.1 \mathrm{~A}$ & 201 \\
\hline & 58 & 8.3 & 190.7 & 2,247 \\
\hline & 72 & 8.4 & 525.3 & 12,779 \\
\hline \multirow[t]{6}{*}{6.90} & 10 & 6.9 & $23.2 \mathrm{~A}$ & $275 \mathrm{~B}$ \\
\hline & 22 & 7.0 & $38.9 \mathrm{~A}$ & $26 \mathrm{~B}$ \\
\hline & 34 & 7.4 & $80.3 \mathrm{~A}$ & $49 \mathrm{~B}$ \\
\hline & 46 & 7.6 & 232.5 & $5,896 \mathrm{~A}$ \\
\hline & 58 & 8.8 & 364.2 & $3,699 \mathrm{~A}$ \\
\hline & 72 & 9.0 & 605.0 & 28,727 \\
\hline
\end{tabular}

Cultures were obtained in unbuffered liquid Kafer medium incubated under static conditions, and growth and $\overline{\text { ST formation were measured as described }}$ in Materials and methods. Statistical analysis of samples $(n=5)$ proceeded by the Tukey test. Values in the same experimental block (same initial $\mathrm{pH}$ ) marked with the same letter in the same column are statistically similar $(\mathrm{p}=0.05)$. 


\section{Transcription of regulatory genes through time of} incubation

The previous experiment suggested a correlation between $\mathrm{pH}$ and ST production. Taking into consideration that both phenomena are regulated in Aspergilli by known pathways $(6,25)$, we decided to investigate the correlation existing between the drift in external $\mathrm{pH}$ during incubation, and the expression of the corresponding regulatory genes. A. nidulans MAD002 was incubated in Kafer medium $\mathrm{pH}=6.60$ for $83 \mathrm{~h}$. Mycelia were collected at different intervals, and levels of transcripts of the regulatory gene aflR was evaluated (Fig. 1). aflR expression levels increased through time linearly $\left(\mathrm{r}^{2}=0.922\right)$ as $\mathrm{pH}$ of the medium was increased, raising the hypothesis that alkaline $\mathrm{pH}$ promotes ST biosynthesis.

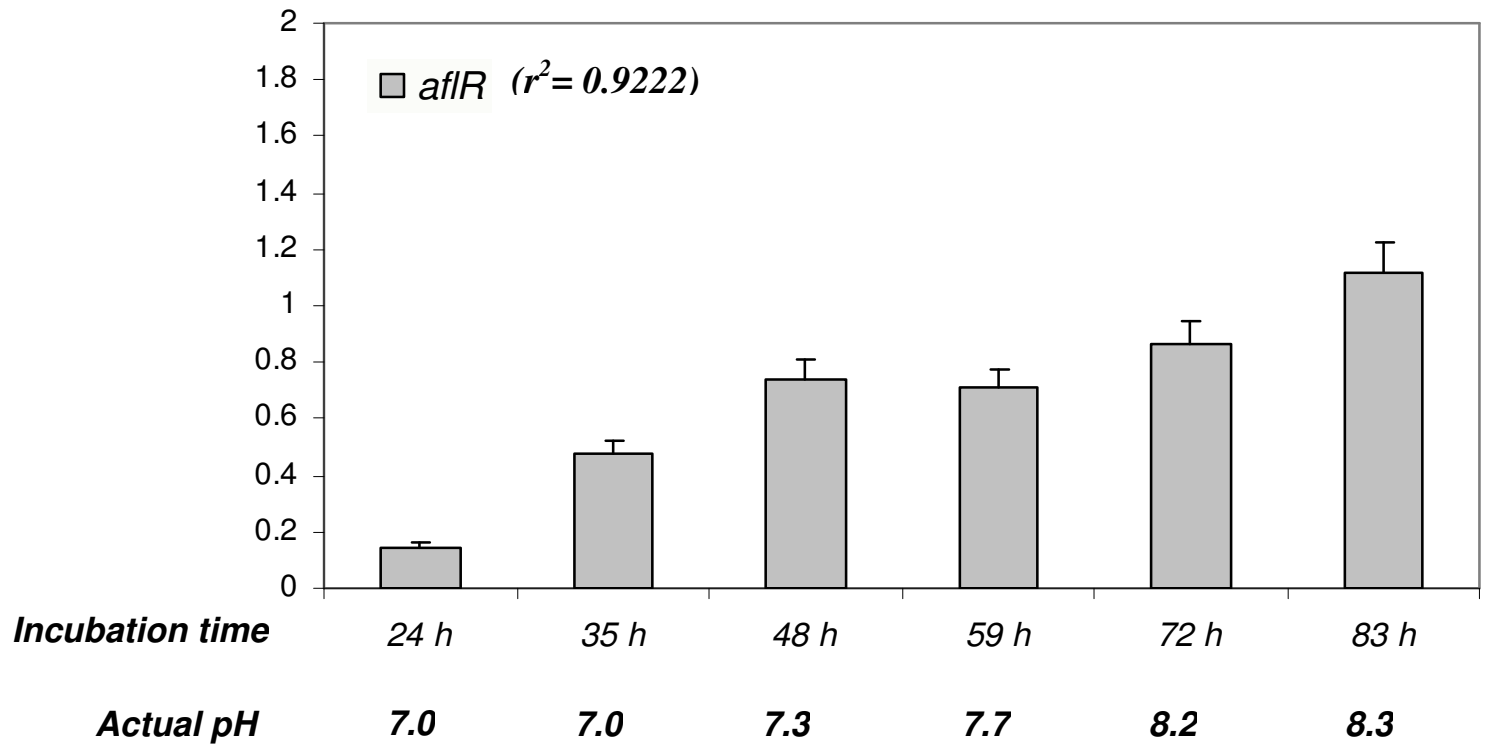

Figure 1. Effect of $\mathrm{pH}$ on the transcription of the regulatory gene aflR in the wild-type strain MAD002 through incubation time. Cultures were incubated in large Petri dishes containing liquid $\mathrm{pH}=6.5$ unbuffered Kafer medium under static conditions at $37{ }^{\circ} \mathrm{C}$. At intervals, sets of dishes were recovered, RNA was extracted and transcription levels were measured by semiquantitative RT-PCR. $\gamma$-actin was used as an endogenous reference. The amount of each mRNA was normalized to the amount of $\gamma$-actin mRNA in each sample. Data are means \pm SD $(n=3)$. Time of incubation and actual $\mathrm{pH}$ of the different samples are indicated.

Determination of the optimum $\mathrm{pH}$ for growth and ST production in the wild-type and mutant strains affected in the Pal/Pac pathway

A. nidulans mutants affected in the $\mathrm{Pal} / \mathrm{Pac}$ pathway were included in these experiments because of the general observation on the role of this pathway in the regulation of different phenomena by $\mathrm{pH}$ in Aspergilli. All strains were grown in Kafer (liquid or solid) medium containing $100 \mathrm{mM}$ citrate buffer at different $\mathrm{pH}$ values. It was observed that mycelial growth of wild-type strains (FGSC26 and MAD002) was higher at alkaline pH. ST levels were about 30-70-fold higher at alkaline $\mathrm{pH}$ as compared to acidic or neutral conditions in both strains. In contrast to these results, the $A$. nidulans "acidity mimicking” mutant MAD134 (palAl) grew poorly at these three different $\mathrm{pH}$ values compared to the wild-type strains grown at similar $\mathrm{pH}$ values and time. 
Delgado-Virgen, F. et al.

Interestingly, this mutant was unable to produce ST at any of the $\mathrm{pH}$ values tested. On the other hand, the MAD135 (pacC $C^{c} 14$ ) mutant produced ST regardless of the $\mathrm{pH}$ of the medium. Nevertheless, as previously reported (18), its levels of ST production were well below those from the wild-type strains. These results are shown in Table 2. Finally, contrary to the behavior of strain MAD135, a pacC negative mutant (MAD812) was unable to synthesize ST at neither acid nor alkaline pH (Table 3).

Table 2. Growth and ST synthesis in A. nidulans strains grown in buffered medium.

\begin{tabular}{ccccc}
\hline Strain & Initial pH & Final $\mathbf{~ H ~}$ & Growth $^{\text {a }}$ (mg mycelium) & Total Sterigmatocystin (ng) \\
\hline FGSC26 $(w t)$ & 3.0 & 3.2 & $175 \mathrm{~A}$ & $7,683 \mathrm{~A}$ \\
& 6.5 & 6.4 & $186 \mathrm{~A}$ & $7,477 \mathrm{~A}$ \\
& 8.0 & 8.7 & 406 & 508,799 \\
MAD002 (wt) & 3.3 & 4.1 & $515 \mathrm{~A}$ & $4,249 \mathrm{~A}$ \\
& 6.2 & 8.4 & 356 & $2,158 \mathrm{~A}$ \\
MAD134 (palA1) & 3.3 & 3.5 & $562 \mathrm{~A}$ & 141,097 \\
& 6.1 & 6.1 & 70.4 & 0 \\
MAD135 & 7.9 & 7.6 & $57.3 \mathrm{~A}$ & 0 \\
(pacC 14$)$ & 3.3 & 3.5 & $35.6 \mathrm{~A}$ & $463 \mathrm{~A}$ \\
& 6.1 & 6.2 & $130.5 \mathrm{~A}$ & $229 \mathrm{~A}$ \\
\hline
\end{tabular}

Cultures were obtained in buffered (100 mM citrate) liquid Kafer medium incubated under static conditions, and growth and ST formation were measured as described in Materials and methods. Statistical analysis of samples $(\mathrm{n}=5)$ proceeded by the Tukey test $(\mathrm{p}=0.05)$. Statistical significance of the differences in the same experimental block (same strain and medium) were treated as described for Table 1.

Table 3. Growth and ST synthesis of A. nidulans MAD002 and MAD812 strains grown in solid buffered medium.

\begin{tabular}{ccccc}
\hline Strain & Initial pH & Final pH & Growth (mg1) & Total ST \\
\hline MAD002 (wt) & 3.1 & 4.4 & $726.9 \mathrm{~A}$ & 29,076 \\
& 7.8 & 8.9 & $747.0 \mathrm{~A}$ & $2 ’ 530,700$ \\
MAD812 (pacC (209) $^{+/ 2}$ & 3.1 & 4.0 & 707.3 & 0 \\
& 7.8 & 8.3 & 260.6 & 0 \\
\hline
\end{tabular}

Cultures were obtained in buffered (100 mM citrate) solid Kafer medium, and growth and ST formation were measured as described in Materials and methods. Statistical analysis of samples $(n=5)$ proceeded by the Tukey test $(\mathrm{p}=0.05)$. Statistical significance of the differences in the same experimental block (same strain and medium) were treated as described for Table 1.

Determination of the expression of regulatory genes in wild-type and mutants affected in the Pal/Pac pathway

In order to analyze the effect of $\mathrm{pH}$ on the expression of the regulatory genes ( $\mathrm{pacC}$ and aflR) in wild-type and $\mathrm{Pal} / \mathrm{Pac}$ affected mutants, we used buffered medium of different $\mathrm{pH}$ values as described above. It was observed that expression levels of pacC and $a f l R$ in strain FGSC26 increased linearly as $\mathrm{pH}$ of the medium increased $\left(\mathrm{r}^{2}=0.981\right.$ and $\mathrm{r}^{2}=0.997$, respectively). Expression levels of pacC in strain MAD134 (palAl) remained low and constant at all $\mathrm{pH}$ values. aflR 
levels were also basal, in agreement with the absence of ST production at any $\mathrm{pH}$ value. Transcript levels from strain MAD135 ( acC $^{c} 14$ ) contrasted with those of strain MAD134 (palA1). Levels of pacC transcript in $p_{a c} C^{c} 14$ were twice higher than those from palAl mutant, and its aflR transcript levels were high regardless of the $\mathrm{pH}$ of the medium, correlating with ST production in this strain (these results are shown in Fig. 2).
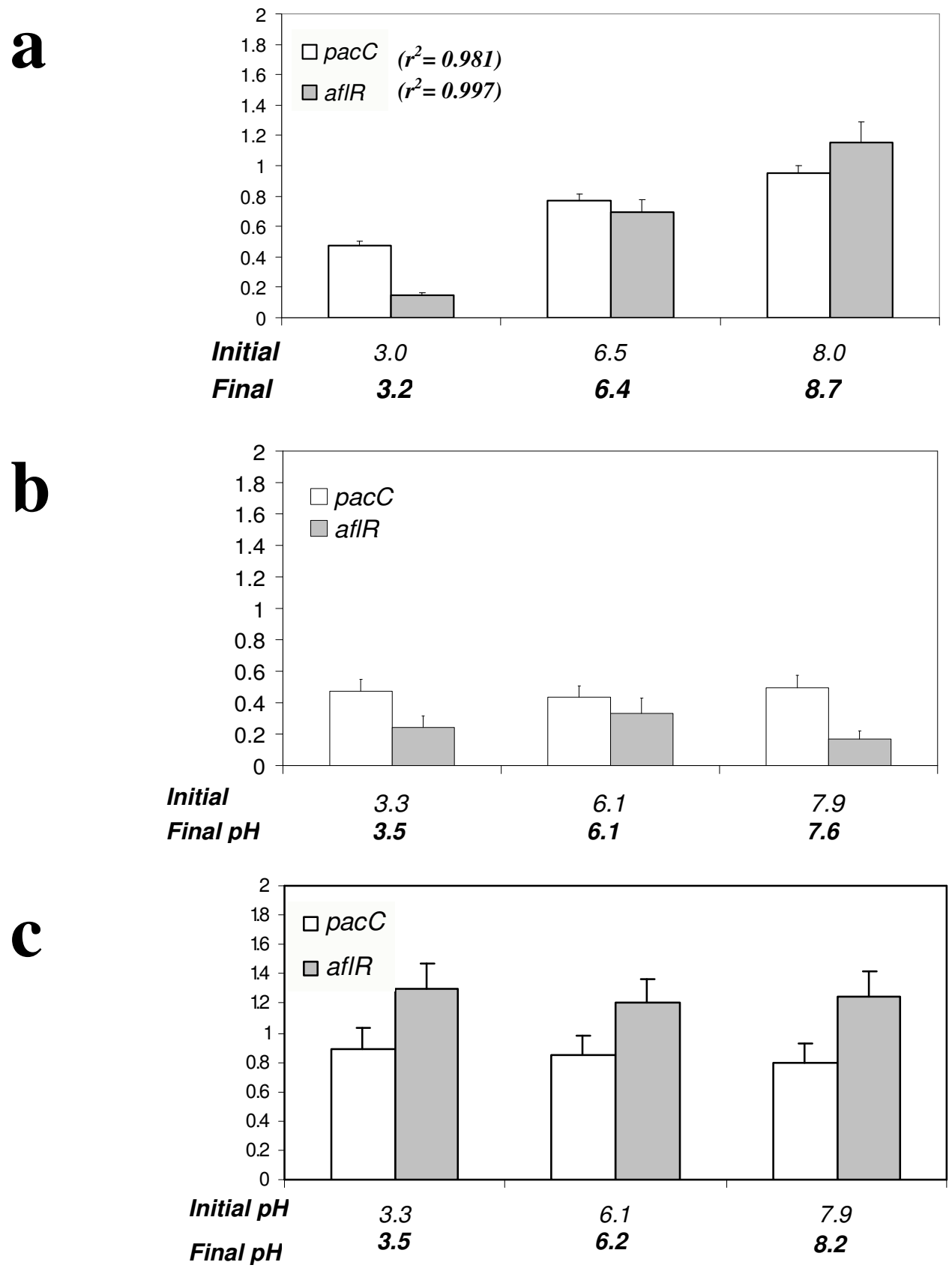

Figure 2. Effect of $\mathrm{pH}$ on the transcription of pacC and aflR genes in wild-type and mutant strains of A. nidulans grown at three different $\mathrm{pH}$ values. Culture conditions proceeded as described for Fig. 1, but medium was added of $100 \mathrm{mM}$ citrate buffer at the indicated $\mathrm{pH}$ values, and incubation lasted for $72 \mathrm{~h}$. Gene transcription levels were analyzed as described for Fig. 1. Data are means $\pm \mathrm{SD}(\mathrm{n}=3)$. a) wild-type strain FGSC26; b) "acidity mimicking" mutant MAD134 (palA1); c) "alkalinity mimicking" mutant MAD135 (pac $\left.C^{c} 14\right)$. Initial and final pH values of the different samples are indicated. 
Effect of pH on the regulatory mechanism of ST synthesis

We further proceeded to determine the probable level at which external pH affects ST production. It has been suggested that $f l u G$ and $f l b A$ encoded proteins have a positive role in ST production (17). In this model, laeA transcript product also activates ST formation (3). Transcript levels of these genes were evaluated in FGSC26 and MAD134 (palAl) strains grown at three different $\mathrm{pH}$ values in citrate buffered medium for $72 \mathrm{~h}$ (Fig. 3). It was noted that $f l u G\left(\mathrm{r}^{2}=0.998\right.$ in wild-type and $\mathrm{r}^{2=} 0.971$ in MAD134 strains) and flbA $\left(\mathrm{r}^{2}=\right.$ 0.889 and $r^{2=} 0.976$, respectively) were preferentially expressed at alkaline $\mathrm{pH}$ in both strains. On the other hand transcript levels of laeA were higher at neutral and alkaline $\mathrm{pH}$ in the wild-type strain (Fig. 3), but in the MAD134 (palA1) strain an opposite trend in expression was observed, decreasing with an increase in $\mathrm{pH}$ (data not shown).

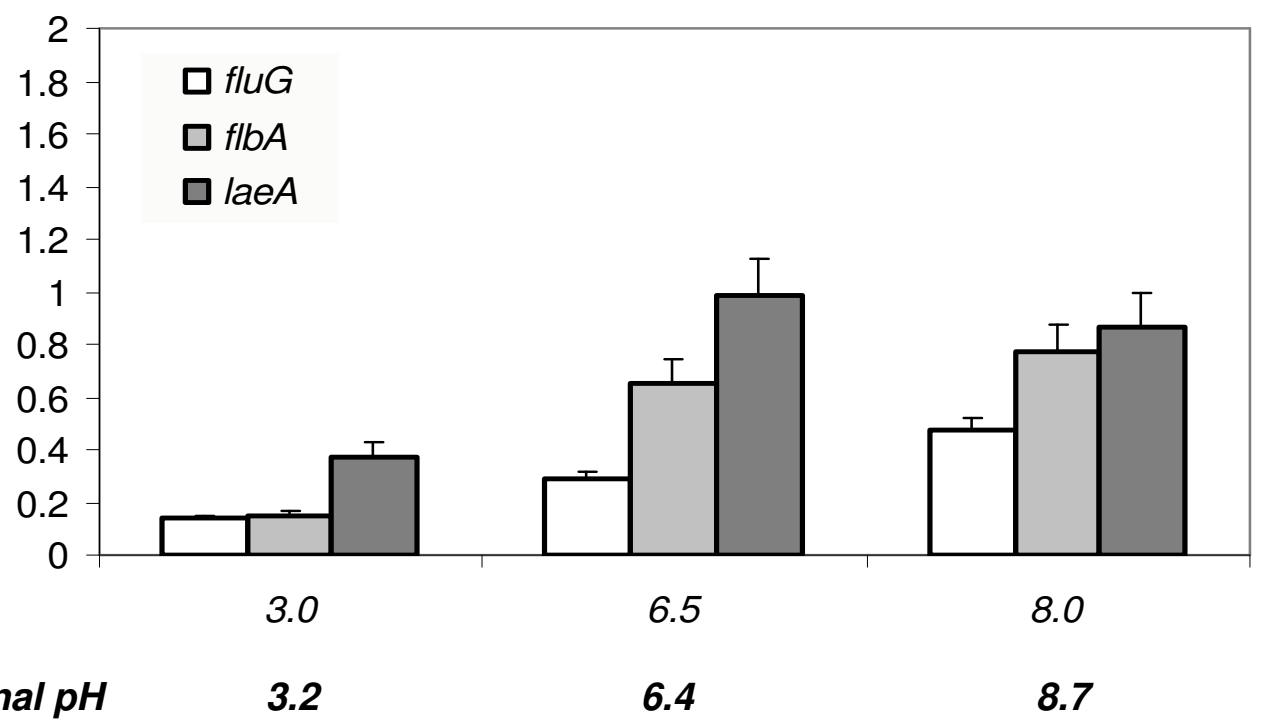

Figure 3. Effect of $\mathrm{pH}$ on the transcription of $f l u G, f l b A$ and laeA genes in the wild-type strain FGSC26 grown at three different $\mathrm{pH}$ values. Culture conditions proceeded as described for Fig. 2, and transcription levels were analyzed as described for Fig. 1. Data are means $\pm \operatorname{SD}(n=3)$.

\section{DISCUSSION}

The formation of natural products resulting from the secondary metabolism of plants and microorganisms is subjected to different environmental cues, such as temperature, humidity, light, $\mathrm{pH}$, nutrient source, etc. Aflatoxins (AF), probably the most important and studied mycotoxins, do not escape to this rule. Accordingly, it has been described that temperature and nitrogen source affect AF production in A. parasiticus and ST synthesis in $A$. nidulans, but in different ways (11). It was demonstrated that nitrate as the sole nitrogen source promoted ST synthesis in
A. nidulans, while ammonium promoted AF production in $A$. parasiticus. It was also observed that AF production by $A$. parasiticus was best at $27{ }^{\circ} \mathrm{C}$, while ST was maximally produced by $A$. nidulans when incubated at $37^{\circ} \mathrm{C}(11)$.

$\mathrm{pH}$ is also an important factor in the production of aflatoxins. Acid $\mathrm{pH}$ has been described to stimulate $\mathrm{AF}$ synthesis in A. parasiticus $(10,18)$. According to the results described in this paper, we may conclude that $\mathrm{pH}$ of the medium does have an effect on ST synthesis in A. nidulans, with alkaline $\mathrm{pH}$ promoting mycotoxin production. These data are in contradiction with a previous communication reporting stimulation of ST biosynthesis at acid $\mathrm{pH}$ (18). The 
reasons for this discrepancy are difficult to pin point. Possibly, conditions of growth, time of incubation and the determination only of ST present in the mycelium (contrary to our protocols) may be partially responsible for this behavior.

Among our data that support the conclusion that it is alkaline $\mathrm{pH}$ the one that promotes ST production, we may cite the following: 1) the repeated observation that higher levels of $\mathrm{ST}$ are produced at alkaline $\mathrm{pH}$ in the wild-type strains; 2) the observation that expression levels of aflR (the transcriptional regulator of the gene cluster encoding proteins involved in ST synthesis (24)) in the wild-type strain of $A$. nidulans were high under alkaline conditions, and very low at acidic $\mathrm{pH}$; 3) the observation that an "acidity mimicking” palA mutant did not produce ST at any $\mathrm{pH}$ value; 4) the observation that a PacC constitutive "alkalinity mimicking" mutant produced similar levels of ST at all the $\mathrm{pH}$ values tested, although as reported (18), at lower levels than the wild-type strain; 5) the fact that a pacC negative mutant did not form ST at any pH value. These last results also meet the criteria for recognizing gene regulation by $\mathrm{pH}$ through the $\mathrm{Pal} / \mathrm{Pac}$ signaling pathway (1); and finally 6) it is also important to point out that the regulation of other genes involved in the common control of ST biosynthesis (laeA, $f l u G$ and $f l b A$ ) are in agreement with a positive regulation by alkaline $\mathrm{pH}$.

It is accepted that LaeA is a global regulator of secondary metabolism in A. nidulans (2). Levels of transcription of laeA gene were higher at neutral to alkaline growth conditions in the wild-type strain.

$f l u G$ and $f l b A$ are known to be involved in a Gprotein/cAMP/PKA signaling pathway that connects ST synthesis and development in A. nidulans $(3,14)$. The observation that transcription of both genes was stimulated by alkaline $\mathrm{pH}$ of the medium agrees with the general observation that sterigmatocystin production is stimulated at alkaline $\mathrm{pH}$.

In summary, based on our results, we may suggest that alkaline $\mathrm{pH}$ regulates the signaling pathway that controls ST synthesis in A. nidulans at the level of aflR by the Pal/Pac signaling pathway.

\section{ACKNOWLEDGMENTS}

We wish to thank Prof. Miguel A. Peñalva for providing us all of the A. nidulans MAD strains, and to Prof. José Ruiz Herrera for his helpful comments and suggestions to this manuscript. We acknowledge technical support to Gloria Laura Anguiano-Ruvalcaba and Yolanda Rodriguez-Aza. FDV Ph.D fellowship (181787), was supported by CONACYT, México

\section{REFERENCES}

1. Arst, H.N. Jr; Peñalva, M.A. (2003). Recognizing gene regulation by ambient pH. Fungal Genet. Biol, 40, 1-3.

2. Bok, J.W.; Keller, N.P. (2004). LaeA, a regulator of secondary metabolism in Aspergillus spp. Eukaryotic cell 3, 527-535.

3. Brodhagen, M.; Keller, N.P. (2006). Signaling pathways connecting mycotoxin production and sporulation. Mol. Plant Pathol. 7, 285-301.

4. Brown, D.W.; Yu, J.H.; Kelkar, H.S.; Fernandes, M.; Nesbitt, T.C.; Keller, N.P.; Adams, T.H.; Leonard, T.J. (1996). Twenty-five coregulated transcripts define a sterigmatocystin gene cluster in Aspergillus nidulans. Proc. Natl. Acad. Sci. USA 93, 1418-1422.

5. Buchanan, R.L.; Ayres, J.C. (1975). Effect of initial pH on aflatoxin production. Appl Microbiol. 30, 1050-1051.

6. Caddick, M.X.; Brownlee, A.G.; Arst, H.N.Jr. (1986). Regulation of gene expression by $\mathrm{pH}$ of the growth medium in Aspergillus nidulans. Mol. Gen. Genet. 203, 346-353.

7. Calvo, A.M.; Wilson, R.A.; Bok, J.W.; Keller, N.P. (2002). Relationship between secondary metabolism and fungal development. Microbiol. Mol. Biol. Rev. 66, 447-459.

8. Cardwell, K.F.; Desjardins, A.; Henry, H.S.; Munkvold, G., Robens, J. (2001). Mycotoxins: The cost of achieving food security and food quality. APSnet.org. Available at: http://apsnet.org/online/feature/mycotoxin/top.html. Accessed 13 Feb 2009.

9. Cotty, P.J. (1988). Aflatoxin and sclerotial production by Aspergillus flavus: Influence of pH. Phytopathology 78, 1250-1253.

10. Detroy, R.W.; Hesseltine, C.W. (1969). Net synthesis of ${ }^{14}$ C-labeled lipids and aflatoxins in resting cells of Aspergillus parasiticus. Dev. Ind. Microbiol. 10, 127-133.

11. Feng, G.H.; Leonard, T.H. (1998). Culture conditions control expression of the genes for aflatoxin and sterigmatocystin biosynthesis 
in Aspergillus parasiticus and A. nidulans. Appl. Environ. Microbiol. 64, 2275-2277.

12. Guzman-de-Peña, D.; Ruiz-Herrera, J. (1997). Relationship between aflatoxin biosynthesis and sporulation in Aspergillus parasiticus. Fungal Gen. Biol. 21, 198-205.

13. Guzman-de-Peña, D.; Aguirre, J.; Ruiz-Herrrera, J. (1998). Corrrelation between the regulation of sterigmatocystin biosynthesis and asexual and sexual sporulation in Emericella nidulans. Antonie Van Leeuwenhock. 73, 199-205.

14. Hicks, J.K.; Yu, J.H.; Keller, N.P.; Adams, T.H. (1997). Aspergillus sporulation and mycotoxin production both require inactivation of the FadA Ga protein-dependent signaling pathway. EMBO J. 16, 49164923.

15. International Agency for Research on Cancer (IARC). (2002). Aflatoxins (Naturally occurring mixtures). Monogr. Eval. Carcinog. Risks. Hum. 82. Available at http://monographs.iarc.fr. Accessed 13 Feb 2009.

16. Kafer, E. (1977). Meiotic and mitotic recombination in Aspergillus and its chromosomal aberrations. Adv. Genet. 19, 131-133.

17. Keller, N.P.; Kantz, N.J.; Adams, T.H. (1994). Aspergillus nidulans $v e A$ is required for production of the mycotoxin sterigmatocystin. Appl. Environ. Microbiol. 60, 1444-1450.

18. Keller, N.P.; Nesbitt, C.; Sarr, B.; Phillips, T.D.; Burow, G.B. (1997). $\mathrm{pH}$ regulation of Sterigmatocystin and Aflatoxin Biosynthesis in Aspergillus spp. Phytopathology. 87, 643-648.
19. Payne, G.A.; Brown, M.P. (1998). Genetics and physiology of aflatoxin biosynthesis. Annu. Rev. Phytopathol. 36, 329-362.

20. Peñalva, M.A.; Arst, H.N. Jr. (2002). Regulation of gene expresión by ambient $\mathrm{pH}$ in filamentous fungi and yeasts. Microbiol. Mol. Biol. Rev. $66,426-446$.

21. Peñalva, M.A.; Arst, H.N.Jr. (2004). Recent advances in the characterization of ambient $\mathrm{pH}$ regulation of gene expression in filamentous fungi and yeasts. Ann. Rev. Microbiol. 58, 425-451.

22. Task Force Report. (2003). Fungal growth and mycotoxin development by major mycotoxigenic fungi. In Mycotoxins: Risks in plant, animal, and human systems, pp. 129-135. Edited by the Council for Agricultural Science and Technology. CAST, Ames, Iowa, USA.

23. Tilburn, J.; Sarkar, S.; Widdick, D.A.; Espeso, E.A.; Orejas, M.; Mungroso, J.; Peñalva, M.A.; Arst, H.N.Jr. (1995). The Aspergillus PacC zinc finger transcription factor mediates regulation of both acidand alkaline-expressed genes by ambient pH. EMBO J. 14, 779-790.

24. Woloshuk, C.P.; Foutz, K.R.; Brewer, J.F.; Bathnagar, D.; Cleveland, T.E.; Payne, G.A. (1994). Molecular characterization of aflR, a regulatory locus for aflatoxin biosynthesis. Appl. Environ. Microbiol. 60, 2408-2414.

25. Yu, J.; Chang, P.K.; Erlich, K.C.; Cary, J.W.; Bhatnagar, D.; Cleveland, T.E.; Payne, G.A.; Linz, J.E.; Woloshuk, C.P.; Bennet, J.W. (2004). Clustered pathway genes in aflatoxin biosynthesis. Appl. Environ. Microbiol. 70, 1253-1262. 